\title{
Immunity-related genes in Ixodes scapularis-perspectives from genome information
}

\author{
Alexis A. Smith and Utpal Pal* \\ Department of Veterinary Medicine, Virginia-Maryland Regional College of Veterinary Medicine, University of Maryland, College Park, MD, USA
}

\section{Edited by:}

Tanja Petnicki-Ocwieja, Tufts

University School of Medicine and

Tufts Medical Center, USA

\section{Reviewed by:}

Janakiram Seshu, The University of Texas at San Antonio, USA

Yongqun "Oliver" He, University of

Michigan Medical School, USA

${ }^{*}$ Correspondence:

Utpal Pal, Department of Veterinary Medicine, University of Maryland,

Building 795, Room 1341, 8075

Greenmead Drive, College Park,

MD 20742, USA

e-mail: upal@umd.edu
Ixodes scapularis, commonly known as the deer tick, transmits a wide array of human and animal pathogens including Borrelia burgdorferi. Despite substantial advances in our understanding of immunity in model arthropods, including other disease vectors, precisely how I. scapularis immunity functions and influences persistence of invading pathogens remains largely unknown. This review provides a comprehensive analysis of the recently sequenced I. scapularis genome for the occurrence of immune-related genes and related pathways. We will also discuss the potential influence of immunity-related genes on the persistence of tick-borne pathogens with an emphasis on the Lyme disease pathogen $B$. burgdorferi. Further enhancement of our knowledge of tick immune responses is critical to understanding the molecular basis of the persistence of tick-borne pathogens and development of novel interventions against the relevant infections.

Keywords: ticks, Ixodes scapularis, Borrelia burgdorferi, immunity-related genes, innate response, genomics

\section{INTRODUCTION}

Although several hundred tick species are known to exist (Jongejan and Uilenberg, 2004), only a handful transmit human diseases. Ixodes scapularis is one of the predominant tick species that spread a wide array of serious human and animal pathogens, including Borrelia burgdorferi, which causes Lyme borreliosis (Burgdorfer et al., 1982; Anderson, 1991). Our understanding of arthropod innate immune responses, primarily involving the fruit fly and mosquito, has advanced over the past decades (Vilmos and Kurucz, 1998). However, our knowledge of tick immune responses, especially the occurrence of immune-related genes, pathways, and specifically how these components respond to invading pathogens remains under-explored. Notably, many pathogens that persist in and transmit through ticks are evolutionarily distinct and possess unique structures (Hajdusek et al., 2013). For example, key pattern recognition molecules (PAMPs), such as peptidoglycan (PG) and lipopolysaccharides (LPS), are structurally different or completely absent, respectively, in major tick-borne pathogens, such as in B. burgdorferi (Schleifer and Kandler, 1972; Takayama et al., 1987; Fraser et al., 1997). Thus, the wealth of knowledge generated in other model arthropods, especially regarding the genesis of host immune responses against classical Gram-positive or Gram-negative bacterial pathogens, might not be readily applicable for tick-borne pathogens, like B. burgdorferi. The primary goal of this review is to present a general overview of tick immune components, as gathered from the sequenced genome and published data, and discuss their potential for modulating infection, with a focus on a major tick-borne pathogen, B. burgdorferi. A better understanding of the I. scapularis immune response to invading pathogens could contribute to the development of new strategies that interfere with relevant pathogen persistence and transmission.
While a number of studies detailed characterization of I. scapularis proteins, predominantly salivary gland proteins, that influence immunity and pathogen persistence in the vertebrate hosts (Wikel, 1996; Das et al., 2001; Gillespie et al., 2001; Narasimhan et al., 2002, 2004, 2007; Hovius et al., 2008; Dai et al., 2010; Pal and Fikrig, 2010; Kung et al., 2013), relatively limited information is available on how tick proteins shape vector immunity and influence pathogen persistence. In order to generate a list of tick immune genes and related pathways, we sought to perform a comprehensive analysis of the recently sequenced $I$. scapularis genome data that are available through several publicly accessible databases (Hill and Wikel, 2005; Pagel Van Zee et al., 2007). To accomplish this, we initially searched the National Institute of Allergy and Infectious Diseases Bioinformatics Resource Center (www.vectorbase.org) for annotated I. scapularis immune-related genes. In addition, we also reviewed the relevant literature to identify additional innate immune genes, including those discovered in related tick species (Rudenko et al., 2005) or in fruit fly, mosquito, and mammalian genomes (Sonenshine, 1993; Hoffmann et al., 1999; Dimopoulos et al., 2000; Christophides et al., 2002; Hoffmann and Reichhart, 2002; Janeway and Medzhitov, 2002; Govind and Nehm, 2004; Osta et al., 2004; Saul, 2004; Tanji and Ip, 2005; Dong et al., 2006; Ferrandon et al., 2007; Tanji et al., 2007; Jaworski et al., 2010; Kopacek et al., 2010; Yassine and Osta, 2010; Valanne et al., 2011). The latter information was then used to search for possible Ixodes orthologs via BLASTP against the VectorBase database. In total, 234 genes were identified and categorized into one of the following nine major immune pathways or components (number of unique genes): gut-microbe homeostasis (17), agglutination (37), leucine-rich repeat (LRR) proteins (21), proteases (33), coagulation (11), non-self recognition and signal transduction via Toll, IMD, and 
JAK-STAT pathways (55), free radical defense (13), phagocytosis (33), and anti-microbial peptides (14). These genes are listed in Tables 1-9; unless stated otherwise, all annotations are based on the VectorBase database. We recognize that although our list might not be comprehensive as there might be additional published data inadvertently overlooked in our literature/database searches or yet-to-be identified genes involved in tick immune defense, we believe that it still represents the majority of genes that are potentially involved in the tick immune response. In the following sections, occurrence of these components and pathways are systematically discussed for their occurrence in the tick genome; we also highlighted their potential influence on the persistence and transmission of tick-borne pathogens like B. burgdorferi.

\section{SCAPULARIS GENOME}

The I. scapularis genome is relatively large, approximately 2.1 $\mathrm{Gb}$ in size and contains nearly $70 \%$ repetitive DNA (Ullmann et al., 2005). Recently it was completely sequenced by the I. scapularis genome project - a partnership between a number of tick research communities and institutions (Hill and Wikel, 2005; Pagel Van Zee et al., 2007). Toward the end of 2008, sequencing centers announced the annotation and release of the whole genome sequence data (IscaW1, 2008; GenBank accession ABJB010000000). The sequence data were derived from purified genomic DNA preparations isolated from an in-bred tick colony and sequenced to approximately 6 -fold coverage using a combined whole genome shotgun and clone-based approach. The genome information are organized and displayed by a bioinformatics resource center focused on invertebrate vectors of human disease called VectorBase (www.vectorbase.org), which is funded by the National Institute of Allergy and Infectious Diseases, National Institutes of Health. The I. scapularis gene

Table 1 | Gut-microbe homeostasis.

Annotation
Dual oxidase
Phospholipid-hydroperoxide glutathion
peroxidase, putative
Phospholipid-hydroperoxide glutathion
peroxidase, putative
Glutathione peroxidase, putative
Peroxidase
Peroxidase
Glutathione peroxidase, putative
Oxidase/peroxidase, putative
Phospholipid-hydroperoxide glutathion
peroxidase, putative
Oxidase/peroxidase, putative
Oxidase/peroxidase, putative
Peroxidase
Glutathione peroxidase, putative
Oxidase/peroxidase, putative
Peroxidase
Thioredoxin peroxidase, putative
Glutathione peroxidase, putative

Accession number

ISCW007865

ISCW019584

ISCW022517

ISCW020571

ISCW017070

ISCW022537

ISCW008495

ISCW002528

ISCW015098

ISCW017368

ISCW005828

ISCW024650

ISCW020569

ISCW018825

ISCW013159

ISCW013767

ISCW001759

counts included 20,486 high confidence protein-coding genes, 316 non-coding genes and 20,771 transcripts. While the most recent release (IscaW1.3; 2014) reported no modifications of protein-coding loci, it incorporated a new prediction for 285 non-coding RNAs.

\section{IMMUNITY-RELATED GENE/PATHWAYS IN I. SCAPULARIS GUT MICROBE HOMEOSTASIS}

Gut microbiota serve a critically important function in shaping host immunity in a number of organisms, including model arthropods (Dillon and Dillon, 2004; Round and Mazmanian, 2009; Hooper et al., 2012; Buchon et al., 2013; Kamada et al., 2013; Schuijt et al., 2013). Characterization of gut microbiota

Table 2 | Agglutination.

\section{Annotation}

Ferritin

Beta-galactosidase

Ubiquitin associated domain containing protein

Chitin bindin peritrophin A

Beta-galactosidase precursor

galectin, putative

Manose binding ER-golgi comparment lectin

Ixoderin precursor

Ixoderin precursor

Ixoderin B

Ixoderin B

Hemelipoglycoprotein precursor

Ferritin

galectin, putative

Beta-galactosidase

Beta-galactosidase precursor

Beta-galactosidase precursor

Beta-galactosidase precursor

Hemelipoglycoprotein precursor

fatty acyl-CoA elongase, putative

Galectin

Ixoderin Precursor

Hemelipoglycoprotein precursor

Sodium/proton exchanger

C-Type Lectin, Putative

Ixoderin Precursor

Double sized immunoglobulin g binding protein A

Galectin

Hemelipoglycoprotein precursor

Beta-galactosidase precursor

Lectin, Putative

Galectin

Hemelipoglycoprotein precursor

Hemelipoglycoprotein precursor

Ixoderin precursor

Ubiquitin associated and $\mathrm{SH} 3$ domain containing

protein B

Galectin, putative
Accession number

ISCW015079

ISCW000651

ISCW023764

ISCW006076

ISCWOI9676

ISCW008553

ISCW016179

ISCW002664

ISCW022063

ISCW013797

ISCW003711

ISCW012423

ISCW023334

ISCW020268

ISCW019681

ISCW019677

ISCW019679

ISCW016637

ISCW024299

ISCW010899

ISCW020268

ISCW024686

ISCW0I2424

ISCW008652

ISCW010467

ISCW013746

ISCW021766

ISCW008553

ISCW021704

ISCW019678

ISCW012623

ISCW020586

ISCW014675

ISCW021709

ISCW012248

ISCW02I035

ISCW020586 
Table 3 | Leucine-rich repeat (LRR) proteins.

\begin{tabular}{lc}
\hline Annotation & Accession number \\
\hline Lumicans & ISCW001027 \\
LRR (in flii) interacting protein & ISCW016609 \\
Lumicans & ISCW005645 \\
F-Box/LRR protein, putative & ISCW000110 \\
F-Box/LRR protein, putative & ISCW010598 \\
F-Box/LRR protein, putative & ISCW010597 \\
F-Box/LRR protein, putative & ISCW010599 \\
LRR protein, putative & ISCW008095 \\
LRR protein & ISCW014626 \\
F-Box/LRR protein, putative & ISCW010347 \\
F-Box/LRR protein, putative & ISCW005273 \\
LRR and NACHT domain containing protein & ISCW004678 \\
LRR and NACHT domain containing protein & ISCW001292 \\
LRR protein & ISCW012038 \\
F-Box/LRR protein, putative & ISCW016452 \\
F-Box/LRR protein, putative & ISCW018961 \\
F-Box/LRR protein, putative & ISCW013925 \\
LRR containing G-protein coupled receptor & ISCW015788 \\
F-Box/LRR protein, putative & ISCW018134 \\
F-Box/LRR protein, putative & ISCW008236 \\
LRR protein, putative & ISCW003174 \\
\hline
\end{tabular}

in ticks, including I. scapularis, as well as their influence on the persistence of tick-borne pathogens like B. burgdorferi has been a focus of a number of recent studies (Clay et al., 2008; Carpi et al., 2011; Narasimhan et al., 2014). As many of these gut microbes play a beneficial role in the physiology of the host, the immune system therefore must be able to differentiate between commensal microbes and pathogenic microorganisms (Macpherson and Harris, 2004). While mechanisms that contribute to the microbial surveillance and pathogen elimination while tolerating the indigenous microbiota remain obscure in ticks, these are wellresearched in many arthropods, particularly in D. melanogaster (Buchon et al., 2013). Studies have established that immune reactivity within the fly gut ensures preservation of beneficial and dietary microorganisms, while mounting robust immune responses to eradicate pathogens (Buchon et al., 2013). There are at least two models of fly immunity for sensing and preserving beneficial bacterial associations while eliminating potentially damaging ones (Lazzaro and Rolff, 2011). The first occurs by recognition of non-self molecules (invading microbes), while the second involves the recognition of "danger" signals that are released by damaged host cells. However, it is also likely that they work together to maintain effective gut microbe homeostasis. Recent studies suggest that dual oxidase (DUOX) and peroxidases enzymes play a key role in this process (Kim and Lee, 2014). While a number of other regulatory molecules may participate in gut homeostasis, we classified 17 different genes within the I. scapularis genome to this pathway, including a single dual oxidase (DUOX) and several peroxidase proteins (Table 1).

Additional studies have recently detailed how DUOX plays an essential role in gut mucosal immunity and homeostasis (Bae et al., 2010; Deken et al., 2013). DUOX, a member of
Table 4 | Proteases/Protease inhibitors.

\begin{tabular}{|c|c|}
\hline Annotation & Accession numbe \\
\hline Serpin 4 precursor & ISCW023622 \\
\hline Serpin 2 precursor & ISCW010422 \\
\hline Serpin 2 precursor & ISCW018607 \\
\hline Serpin 1 precursor & ISCW023618 \\
\hline Serpin 7 precursor & ISCW024109 \\
\hline PAP associated domain containing protein & ISCW014870 \\
\hline Serpin 7 precursor & ISCW009616 \\
\hline Serine proteinase inhibitor serpin-3 & ISCW015204 \\
\hline Heparan sulfate 2-O sulfotransferase, putative & ISCW000208 \\
\hline Secreted salivary gland peptide & ISCW023621 \\
\hline Serpin & ISCW016489 \\
\hline Hypothetical protein & ISCW017929 \\
\hline Secreted salivary gland peptide & ISCW023620 \\
\hline Serpin 4 precursor & ISCW023623 \\
\hline Protein disulfide isomerase 1 & ISCW002080 \\
\hline Alkaline phosphatase & ISCW023785 \\
\hline Alkaline phosphatase & ISCW003801 \\
\hline Alkaline phosphatase & ISCW004677 \\
\hline Hypothetical protein & ISCW021544 \\
\hline Zinc metalloprotease & ISCW008637 \\
\hline Zinc metalloprotease & ISCW005798 \\
\hline Zinc metalloprotease & ISCW005687 \\
\hline Zinc metalloprotease & ISCW005854 \\
\hline Serpin 8 precursor & ISCW014652 \\
\hline Serpin & ISCW014100 \\
\hline Zinc metalloprotease & ISCW012815 \\
\hline Conserved hypothetical protein & ISCW006169 \\
\hline Serpin 8 precursor & ISCW015349 \\
\hline Zinc metalloprotease & ISCW021286 \\
\hline Serpin 2 precursor & ISCW021417 \\
\hline Serpin 2 precursor & ISCW014779 \\
\hline Secreted serine protease & ISCW014551 \\
\hline Alkaline phosphatase & ISCW000162 \\
\hline
\end{tabular}

Table 5 | Coagulation.

\begin{tabular}{lc}
\hline Annotation & Accession number \\
\hline Proclotting enzyme precursor & ISCW013112 \\
Thrombin inhibitor & ISCW000427 \\
Proclotting enzyme precursor & ISCW000320 \\
Proclotting enzyme precursor & ISCW011206 \\
Proclotting enzyme precursor & ISCW001322 \\
Keratinocyte transglutaminase & ISCW019475 \\
Proclotting enzyme precursor & ISCW011961 \\
Proclotting enzyme precursor & ISCW003779 \\
Proclotting enzyme precursor & ISCW010999 \\
Prostate-specific transglutaminase & ISCW009303 \\
Prostate-specific transglutaminase & ISCW011739
\end{tabular}

the nicotinamide adenine dinucleotide phosphate (NADPH) oxidase NOX family (Geiszt and Leto, 2004), has previously been shown to be a key source of local microbicidal reactive oxygen species (ROS) production within the fly gut (Kim and Lee, 2014). 
Table 6 | Non-self recognition (Toll, IMD, and JAK-STAT pathways).

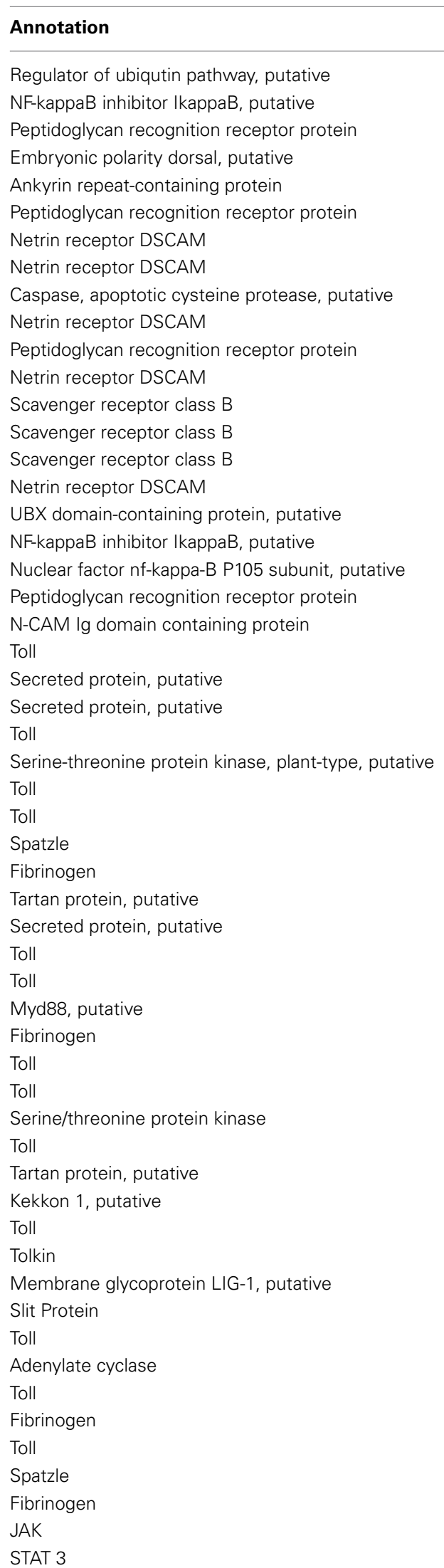

Table 7 | Free radical defense.

\begin{tabular}{lc}
\hline Annotation & Accession number \\
\hline Manganese superoxide dismutase & ISCW016585 \\
Superoxide dismutase & ISCW015027 \\
Manganese superoxide dismutase & ISCW016737 \\
Superoxide dismutase Cu-Zn & ISCW012382 \\
Nitric oxide synthase interacting protein, putative & ISCW017590 \\
Superoxide dismutase & ISCW018077 \\
Superoxide dismutase & ISCW024422 \\
Cu' ${ }^{2+} / \mathrm{Zn}^{2+}$ superoxide dismutase SODI & ISCW011852 \\
Manganese superoxide dismutase & ISCW012767 \\
Superoxide dismutase Cu-Zn & ISCW008219 \\
Ras responsive element binding protein & ISCW009132 \\
Decarboxylase & ISCW021675 \\
Nitric oxide synthase & ISCW018074
\end{tabular}

Table 8 | Phagocytosis.
ISCW019520

ISCW018935

ISCW024689

ISCW022144

ISCW018193

ISCW021005

ISCW024521

ISCW018363

ISCW001463

ISCW004495

ISCW020989

ISCW022569

ISCW009412

ISCW016292

ISCW024389

ISCW007724

ISCW007726

ISCW008802

ISCW009412

ISCW009512

ISCW022740

ISCW020049

ISCW017724

ISCW021508

ISCW018006

ISCW020221

ISCW022120

ISCW005558

ISCW018651

ISCW008289

ISCW012040

ISCW006897

ISCW024309

ISCW007727

ISCW022732

ISCW001478

ISCW016158

ISCW005692
Accession number

ISCW024103

ISCW013741

ISCW015851

ISCW017319

ISCW020822

ISCW005817

ISCW015201

ISCW016805

ISCW005672

ISCW004349

ISCW014238

ISCW004348

ISCW016765

ISCW003282

ISCW003186

ISCW010037

ISCW006741

ISCW003559

ISCW008948

ISCW007121

ISCW019648

ISCW018998

ISCW008875

ISCW002009

ISCW022321

ISCW019271

ISCW018929

ISCW001560

ISCW020878

ISCW011682

ISCW015794

ISCW002553

ISCW003185 
Table 9 | Antimicrobial peptides.

\begin{tabular}{lc}
\hline Annotation & Accession number \\
\hline Putative secreted salivary gland peptide & ISCW005928 \\
Secreted protein, putative & ISCW018425 \\
Secreted salivary gland peptide & ISCW002695 \\
TAK 1 putative & ISCW009364 \\
Secreted salivary gland peptide & ISCW001310 \\
Beta transducin Trp-Asp domain containing protein & ISCW014204 \\
Map kinase activating death domain protein & ISCW017494 \\
Secreted salivary gland peptide & ISCW018541 \\
Defensin & ISCW022102 \\
Preprodefensin putative & ISCW016747 \\
Secreted salivary gland peptide & ISCW002331 \\
Secreted salivary gland peptide & ISCW016466 \\
Secreted salivary gland peptide & AAV63544* \\
Arsenite-resistance protein & ISCW011320 \\
\hline
\end{tabular}

*Based on annotation in NCBI database (http://www.ncbi.nlm.nih.gov).

Targeted depletion of DUOX in flies has resulted in the overproduction of commensal gut bacteria and renders the flies susceptible to infection (Buchon et al., 2013; Kim and Lee, 2014). As originally discovered in Caenorhabditis elegans (Edens et al., 2001), in addition to ROS generation, DUOX is also implicated for catalysis of protein cross-linking that contributes to maintenance of gut microbiota in Anopheles gambiae (Kumar et al., 2010). In mosquitoes, DUOX, along with a specific hemeperoxidase, catalyzes the formation of an acellular molecular barrier, termed dityrosine network (DTN), which forms in the luminal space along the gut epithelial layer during feeding (Kumar et al., 2010). The DTN decreases the gut permeability to various immune elicitors protecting the gut microbiota, both commensal and pathogenic species. Another recent study revealed that an ovarian dual oxidase is essential for insect eggshell hardening through the production of $\mathrm{H}_{2} \mathrm{O}_{2}$, which ultimately promotes protein cross-linking (Dias et al., 2013). Further studies on how DUOX and peroxidase systems maintain gut microbiota in I. scapularis could give novel insight into how pathogens that are transmitted through ticks are able to evade the immune system and persist within the vector.

\section{AGgLUTINATION}

Agglutination, the biological phenomenon by which cells or particles clump together, has been described within various tick species (Uhlir et al., 1996; Kibuka-Sebitosi, 2006). A group of carbohydrate-binding proteins called lectins (Grubhoffer et al., 1997, 2004), which are often produced in a tissue specific manner within arthropods, especially in the gut, hemocytes, or fat bodies, could be key mediators of the process (Grubhoffer et al., 2004, 2005). Agglutination of pathogens by lectins, which also function as host recognition receptors for pathogen-associated molecular patterns (Dam and Brewer, 2010), has been reported in many arthropod vectors, including mosquitoes and tsetse flies, where they play an important role in the pathogen-host relationship (Abubakar et al., 1995, 2006; Barreau et al., 1995; James, 2003). While lectins can function as signaling factors for the maturation of the African trypanosome or as lytic factors (Abubakar et al., 1995, 2006), in mosquitoes they act as agonists of the development of malarial parasites within the vector (Barreau et al., 1995; James, 2003) While tick lectins, particularly those in hard ticks (Ixodidae), have not been studied as extensively as other arthropod lectins, previous reviews summarized available information on lectins of $I$. ricinus (Grubhoffer and Jindrak, 1998; Grubhoffer et al., 2004). Since most lectins isolated from arthropods are the ones from the hemocoel, studies have focused on their localization or hemagglutinating activity in the hemolymph (Sonenshine, 1993; Kuhn et al., 1996). In I. ricinus, this activity was characterized as $\mathrm{Ca}^{2+}$ dependent binding activity (Grubhoffer et al., 2004). A $85 \mathrm{kDa}$ lectin produced by the granular hemocytes and basal laminae surrounding the hemocoel was identified to have a strong binding affinity for sialic acid (Grubhoffer et al., 2004). This immunoreactivity supports the idea that lectins may function as a recognition molecule of the immune system in ticks, implying that they could influence the persistence of tick-borne pathogens like B. burgdorferi. In fact, the hemocytes in $I$. ricinus can also phagocytize $B$. burgdorferi through the coiling method, which has previously been though to be a lectin-mediated process (Grubhoffer and Jindrak, 1998). Specifically, two agglutinins/lectins were isolated from the gut, one $65 \mathrm{kDa}$ and the other $37 \mathrm{kDa}$ in size; the former was shown to be the main agglutinin with a binding affinity for mucin, while the latter protein was found to have a strong affinity for a specific glucan (Grubhoffer and Jindrak, 1998; Grubhoffer et al., 2004). It is also suggested that a gut agglutinin has the potential to bind LPS that in cooperation with other digestive enzymes thought to affect the persistence of Gram-negative bacteria and spirochetes that pass through the gut lumen (Uhlir et al., 1996; Grubhoffer et al., 2004). In addition to hemolymph and gut, lectin activities are also documented in the salivary gland; a $70 \mathrm{kDa}$ protein has been identified as being responsible for the hemagglutinating activity in this organ (Grubhoffer et al., 2004). It is thus possible that lectin or a related protein in the salivary glands could influence pathogen transmission. In fact, a tick mannose-binding lectin inhibitor that is produced in the salivary glands has been shown to interfere with the human lectin complement cascade, significantly impacting the transmission and survival of B. burgdorferi (Schuijt et al., 2011). Taken together, it is likely that lectins could play a role in the immunity of $I$. scapularis, which encodes for at least 37 lectins or related proteins (Table 2 ).

\section{LEUCINE-RICH REPEAT PROTEINS}

LRR have previously been shown to occur in more than 2000 proteins throughout the plant and animal kingdom, including Toll-like receptors, and are thought to play an essential role in host defense (Boman and Hultmark, 1981; Kobe and Kajava, 2001; Bell et al., 2003; Enkhbayar et al., 2004). LRR proteins typically contain 20-29 amino acid residues (with repeats ranging from 2 to 42 ) that are involved in protein-protein interactions with diverse cellular locations and functions. While the biological significance of LRR containing proteins in ticks remains unknown, notably, the $I$. scapularis genome encodes at least 22 potential LRR proteins (Table 3). Unlike in ticks, the roles of LRR proteins in the immunity of other arthropods, including blood-meal 
seeking arthropods, however, are relatively well-characterized (Povelones et al., 2009, 2011). For example, in Anopheles gambiae, LRR-containing proteins, such as LRIM1 and APL1C, have been identified as a potent antagonist of malarial parasites, limiting Plasmodium infection by activating a complement-like system (Fraiture et al., 2009; Povelones et al., 2009, 2011; Baxter et al., 2010). In Manduca sexta, an LRR-containing protein, termed leureptin, is shown to bind lipopolysaccharide and is involved in hemocyte responses to bacterial infection (Zhu et al., 2010). Further studies into how tick LRR-containing proteins contribute to vector immunity and influence pathogen persistence are warranted.

\section{PROTEASES/PROTEASE INHIBITORS}

A number of immune cascades that serve to recognize and control invading pathogens are dependent on the activity of specific proteases or protease inhibitors (Janeway and Medzhitov, 2002; Sojka et al., 2011). Proteases, specifically serine proteases, have previously been shown to be a key regulating molecule for several of these immune response pathways, including coagulation, antimicrobial peptide synthesis, and melanization of pathogens (Gorman and Paskewitz, 2001; Janeway and Medzhitov, 2002; Jiravanichpaisal et al., 2006). Such serine protease-dependent cellular response, for example, as demonstrated for coagulation in the horseshoe crab, manifests through the rapid activation of immune pathways in response to pathogen detection (Hoffmann et al., 1999; Fujita, 2002). Activation of this pathway has been shown to be controlled by three serine proteases: factor $\mathrm{C}$, factor B, and a pro-clotting enzyme (Tokunaga et al., 1987). When LPS is present, clotting factors that are stored within hemocytes are readily released into the hemolymph, which ultimately results in the immobilization of the invading pathogen.

Protease inhibitors also control a variety of proteolytic pathways and are known to play an important role in arthropod immunity (Kanost, 1999). A group of serine protease inhibitors, termed serpins, have been the focus of many recent studies that demonstrate the critical contribution of these proteins to the regulation of inflammation, blood coagulation, and complement activation in mammals (Kanost, 1999). Serpins are also shown to contribute to immunity and physiology in arthropods, as shown in mosquitoes (Gulley et al., 2013) and flies (Reichhart et al., 2011). A detailed characterization of serpins in ticks, including I. scapularis, has been reported by Mulenga et al. (Mulenga et al., 2009). These authors reported the presence of at least 45 serpin genes within the I. scapularis genome, interestingly, most of which are differentially expressed in the gut and salivary glands of unfed and partially fed ticks (Mulenga et al., 2009). It is speculated that ticks could utilize some of these serpins to manipulate host defense to facilitate tick feeding and subsequent disease transmission, although the precise role of serpins in the physiology and immunity within the tick vector awaits further investigation. More recently, a novel serpin, termed IRS-2, was described in I. ricinus (Chmelar et al., 2011). IRS-2 was shown to inhibit cathepsin G and chymase, thereby inhibiting host inflammation and platelet aggregation. This particular protein was also thought to act as a modulator of vascular permeability. Although whether serpins play a role in host microbe interactions remains unknown, studies also explored their potential as target antigens for development of a tick vaccine (Muleng et al., 2001).

\section{COAGULATION}

Injury as well as the presence of microbes in arthropods could result in the induction of two major proteolytic pathways - coagulation and melanization (Theopold et al., 2004). Key enzymes for these processes that cross-link the clot or induce a proteolytic pathway similar to the vertebrate clotting cascade include transglutaminase and phenoloxidase, respectively. Studies in the horseshoe crab have provided a breakthrough in our understanding of the coagulation pathway in arthropods (Theopold et al., 2004). This pathway is characterized by a rapid sequence of highly localized serine proteases and culminates in the generation of thrombin; the process is tightly regulated to ensure excessive clot formation does not occur (Crawley et al., 2011). The I. scapularis genome encodes for at least 11 genes that may be part of the coagulation pathway (Table 5), although precisely how this pathway controls wound healing or affects microbial survival remains unknown. Notably, while the I. scapularis genome lacks genes related to the melanization (phenoloxidase) pathway, phenol oxidase activity was detected in the hemolymph of the soft ticks, Ornithodoros moubata (Kadota et al., 2002).

\section{NON-SELF RECOGNITION AND SIGNAL TRANSDUCTION PATHWAYS (TOLL, IMD, AND JAK-STAT)}

Three major pathways, namely Toll, immune deficiency (IMD), and Janus kinase (JAK)- signaling transducer and activator of transcription (STAT) pathways, contribute to the activation of the immune response within arthropods, as previously detailed (Belvin and Anderson, 1996; De Gregorio et al., 2002; Hoffmann and Reichhart, 2002; Govind and Nehm, 2004; Lemaitre, 2004; Rawlings et al., 2004; Kaneko and Silverman, 2005; Tanji and Ip, 2005; Zambon et al., 2005; Tanji et al., 2007; Xi et al., 2008; SouzaNeto et al., 2009; Valanne et al., 2011; Liu et al., 2012). Notably, the I. scapularis genome encodes many representative genes from all three pathways (Figure 1). While Toll pathways are activated in the presence of bacterial, viral, and fungal pathogens, the IMD pathway is induced by Gram-negative bacteria. The arthropod JAK-STAT pathway, analogous to a cytokine-signaling pathway in mammals (Shuai et al., 1993), has also previously been shown to be activated in the presence of bacterial or protozoan pathogens (Buchon et al., 2009; Gupta et al., 2009; Liu et al., 2012). The Toll pathway is most extensively studied in Drosophila, which encodes nine Toll receptors (Valanne et al., 2011). Cell wall components in Gram-positive bacteria stimulate this pathway, whereas the precise fungal component that induces specific Tolls is not welldefined. In both cases, stimulation of the Toll pathway causes cleavage of the protein Spätzle, which eventually leads to the activation of NF- $\mathrm{B}$ transcription factor family members Dif and Dorsal, which are homologous to mammalian c-Rel and RelA, resulting in the production of different antimicrobial peptides (AMPs) (Irving et al., 2001; Christophides et al., 2002; Hetru et al., 2003). Specifically, research in Drosophila has shown that Gram-positive bacteria induce the Toll pathway, leading to the generation of Toll-specific AMPs, such as drosomycin (Zhang and Zhu, 2009). While roles of Toll pathways in I. scapularis remain 


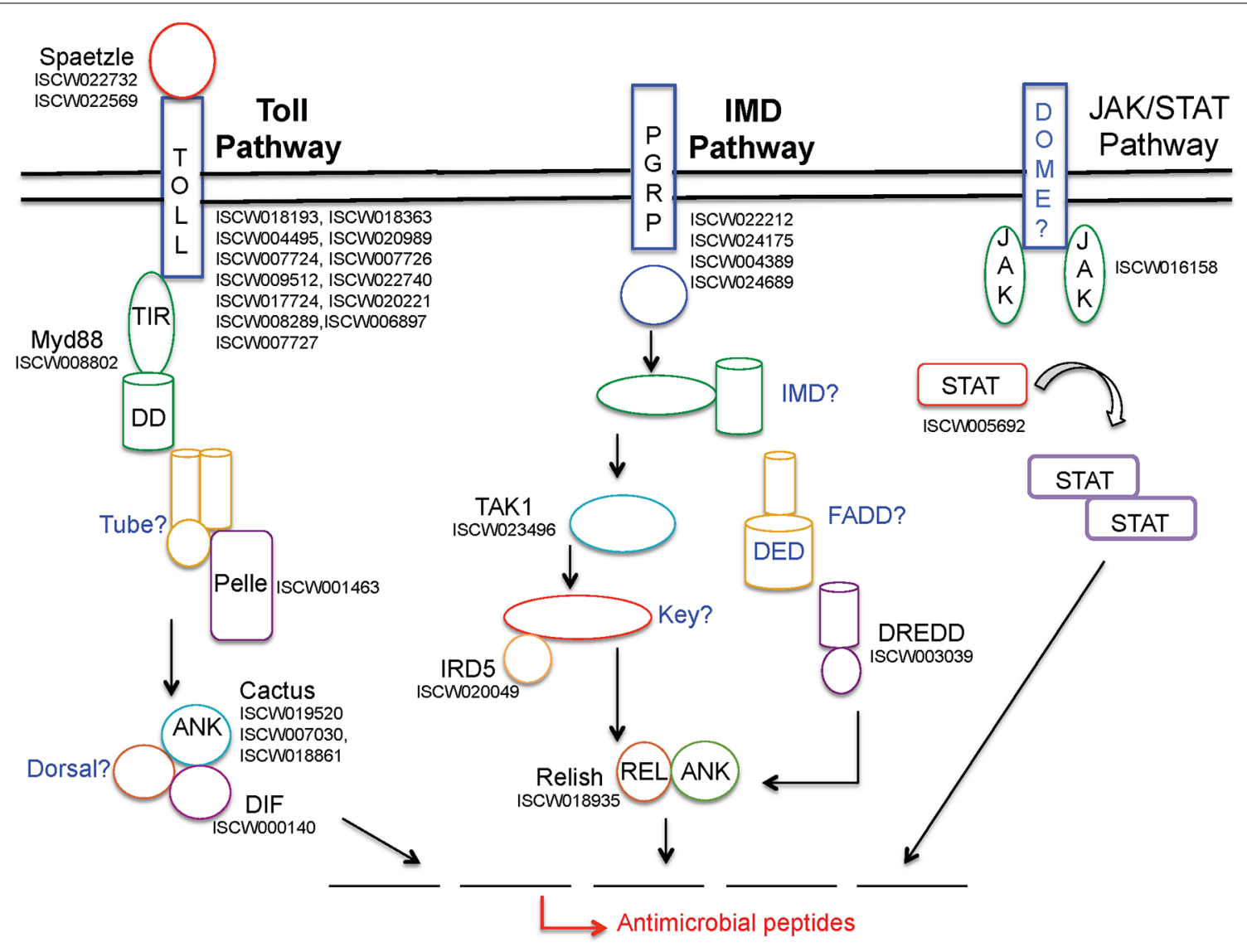

FIGURE 1 | Schematic representation of $I$. scapularis immune-related genes potentially representing three major signaling pathways that lead to anti-microbial responses. While annotated tick genes from each pathway are shown in black font, the apparently missing genes are indicated in blue. For further details on these pathways, including abbreviations, please refer to the text and earlier publications (Lemaitre, 2004; Liu et al., 2012). obscure, we list at least 33 genes that potentially belong to this pathway (Table 6). The IMD pathway, on the other hand, is activated by the peptidoglycan molecules present on the surface of Gram-negative bacteria that are recognized by host cells via peptidoglycan recognition receptors (PGRP) (Ferrandon et al., 2007). This recognition leads to the activation of an adaptor protein and further downstream signaling molecules, such as transcription factor Relish, a compound Rel-Ank protein homologous to mammalian p100 and p105, ultimately resulting in the production of AMPs (Matova and Anderson, 2006; Ferrandon et al., 2007). Although the tick genome encodes at least 20 potential genes from this pathway (Table 6), similar to Toll, how the IMD pathway affects Gram-negative pathogens, including B. burgdorferi is unknown. A critical and common aspect in the response of both pathways is the ability to induce a specific AMP to combat microbial infections through the recognition of non-self. Interestingly, it is also thought that these two pathways can work synergistically to activate the expression of the same AMP (Tanji et al., 2007).

\section{FREE RADICAL DEFENSE}

Free radicals, such as ROS, which include superoxide radicals $(\mathrm{O} \cdot 2)$, hydroxyl radicals $(\cdot \mathrm{OH})$, and other compounds, are able to react with biomolecules and cause damage to DNA, proteins, and lipids, playing as critical role in cell signaling (Thannickal and Fanburg, 2000). While ROS are important in arthropod development (Owusu-Ansah and Banerjee, 2009), they are indispensible in arthropod immunity, including activation of specific immune pathways (Pereira et al., 2001; Bubici et al., 2006; Molina-Cruz et al., 2008; Morgan and Liu, 2011). For example, mosquitoes that were previously infected with Wolbachia bacteria were observed to produce much higher levels of ROS (Pan et al., 2012). Nitric oxide (NOS), a highly unstable free radical gas, is another component of free radical defense shown to be toxic to both parasites and pathogens (James, 1995; Wandurska-Nowak, 2004). In insects, NOS is known to be induced following parasite infection (Dimopoulos et al., 1998; Davies, 2000).

A family of superoxide dismutases (SOD) that catalyze the conversion of these free radicals to non-toxic $\mathrm{O}_{2}$ and less toxic hydrogen peroxide $\left(\mathrm{H}_{2} \mathrm{O}_{2}\right)$ are responsible for destroying any free radicals generated in the hosts. Glutathione-S-transferases (GST) also detoxify stress-causing agents, including toxic oxygen free radical species (Sharma et al., 2004). The genes encoding GSTs are shown to be induced in model arthropods upon oxidative stress and microbial challenge, including in ticks infected with B. burgdorferi (Rudenko et al., 2005). Despite these studies, how different free radicals or SOD detoxification systems play 
roles in pathogen persistence or clearance within I. scapularis, which encodes at least 13 genes of this pathway (Table 7), remains uncharacterized.

\section{PHAGOCYTOSIS}

Cells recognize, bind, and ingest relatively large particles in phagocytosis (Walters and Papadimitriou, 1978). This process is considered a major evolutionarily conserved cellular immune response in arthropods, mostly studied in model insects (Sideri et al., 2008), and is mediated by hemocytes, also known as blood cells, which are primarily present in the hemolymph as well as infrequently exist within various organs. Phagocytosis of microbes plays a critical role in arthropod defense, as blocking of phagocytosis in Drosophila mutants significantly impairs the flies' ability to survive subsequent bacterial infection (ElrodErickson et al., 2000). Hemocytes within the hemolymph have previously been shown to phagocytize various pathogens (Inoue et al., 2001). Whereas, although solid experimental evidence of phagocytosis of B. burgdorferi within I. scapularis is lacking, certain cell lines derived from ticks have been shown to be phagocytic to spirochetes (Mattila et al., 2007). Further studies into the phagocytic pathway of $I$. scapularis, which encodes 33 potentially related genes (Table 8), would provide insight into whether or how pathogens, such as B. burgdorferi, are phagocytized, as well as how tick-borne pathogens are able to escape this cellular immune response. Notably, the I. scapularis genome encodes for five small GTPases belonging to the Rho family that in addition to other cellular functions, are shown to play central roles in phagocytosis (Etienne-Manneville and Hall, 2002; Bokoch, 2005).

\section{ANTI-MICROBIAL PEPTIDES}

The production of AMPs, a hallmark of systemic humoral immune responses, is an important aspect of host defense in arthropods (Bulet et al., 1999). At least eight different classes of AMPs have been observed in the fruit fly, Drosophila. These AMPs, are mainly produced by fat bodies and secreted into the hemolymph and can then be further grouped into three different families based on their intended target: Gram-negative bacteria, Gram-positive bacteria, and fungi (Imler and Bulet, 2005). In arthropods, specific AMPs are produced as a result of activation of the Toll, IMD, or JNK-STAT pathway by the presence of bacteria, fungi, or viruses.

Among effector molecules of innate immune defense, AMPs are relatively well-studied in ticks, which likely generate classical AMPs in the gut and hemocoel (Hynes et al., 2005; Saito et al., 2009). AMPs have been found to be produced in hard ticks, such as I. scapularis and Dermacentor variabilis, as well as in the soft tick Ornithodoros moubata (Nakajima et al., 2002; Sonenshine et al., 2002; Hynes et al., 2005; Rudenko et al., 2005; Saito et al., 2009). I. ricinus induces a defensin-like gene in response to B. burgdorferi in a tissue-specific manner that is not capable of clearing the infection (Rudenko et al., 2005). I. scapularis encodes for at least 14 AMPs (Table 9). The exact role of defensin or other AMPs in clearance of tick-borne pathogens remains unclear. In addition, ticks may also produce non-classical AMPs. Although gastric digestion in ticks is primarily intracellular, degradation of blood components, such as hemoglobin, could create peptides with antimicrobial activities (Sonenshine et al., 2005). Whether these fragments would protect against pathogenic bacteria has currently not been reported.

\section{CONCLUDING REMARKS}

I. scapularis ticks are known to transmit a diverse set of disease agents ranging from bacterial to protozoans to viruses. A number of studies explored the immunomodulatory activities of tick saliva or components of the salivary gland in mammalian hosts or how these activities benefit tick-transmitted pathogens (Hovius et al., 2008; Pal and Fikrig, 2010). However, limited investigation addressed how vector immune responses influence the survival or persistence of specific pathogens within the tick. It is rather surprising that although ticks are known to encode components of a number of immune effector mechanisms, including humoral (classical AMPs) or cellular (phagocytosis) immune responses as well as evolutionary conserved signaling molecules or potentially active pathways (Toll, IMD, or JAK/STAT), their contribution in shaping I. scapularis immunity remains largely obscure. Tick-borne pathogens are evolved to persist and be transmitted by a specific tick species. Thus, it is conceivable that these pathogens coevolved and developed a successful and intimate relationship with the host. Additionally, to be successful in nature, these pathogens must have also evolved specific mechanisms to persist in the vector and evade innate immune insults. For example, when artificially challenged with the Lyme disease pathogen, I. scapularis ticks mount slower phagocytic responses and therefore, remain practically immunotolerant against spirochete infection (Johns et al., 2001). In contrast, another hard tick species, D. variabilis, when challenged with the same pathogen, generates a rapid and effective increase in phagocytic cells and clears the infection and thus, is highly immunocompetent against spirochete infection. With the availability of I. scapularis genome information and development of robust functional genomics and bioinformatics as well as the advent of efficient high-throughput genome sequencing tools, we expect exciting future research enhancing our knowledge of I. scapularis immunity and hope to address specific questions on the biology of tick immune responses against a diverse group of human pathogens. Together, these studies will contribute to a better understanding of the special biology of vector-microbe interaction and specific aspects of tick immunity and at the same time, contribute to the development of new strategies to combat pathogen transmission.

\section{ACKNOWLEDGMENTS}

We are thankful to Faith Kung and Brian Backstedt for their sincere help with the bioinformatics analysis. The study was supported by funding from the National Institutes of Health (AI080615).

\section{REFERENCES}

Abubakar, L., Osir, E. O., and Imbuga, M. O. (1995). Properties of a blood-mealinduced midgut lectin from the tsetse fly Glossina morsitans. Parasitol. Res. 81, 271-275. doi: 10.1007/BF00931529

Abubakar, L. U., Bulimo, W. D., Mulaa, F. J., and Osir, E. O. (2006). Molecular characterization of a tsetse fly midgut proteolytic lectin that mediates differentiation of African trypanosomes. Insect Biochem. Mol. Biol. 36, 344-352. doi: 10.1016/j.ibmb.2006.01.010 
Anderson, J. (1991). Epizootiology of Lyme borreliosis. Scan. J. Infect. Dis. Suppl. $77,23-24$

Bae, Y. S., Choi, M. K., and Lee, W. J. (2010). Dual oxidase in mucosal immunity and host-microbe homeostasis. Trends Immunol. 31, 278-287. doi: 10.1016/j.it.2010.05.003

Barreau, C., Touray, M., Pimenta, P. F., Miller, L. H., and Vernick, K. D. (1995). Plasmodium gallinaceum: sporozoite invasion of Aedes aegypti salivary glands is inhibited by anti-gland antibodies and by lectins. Exp. Parasitol. 81, 332-343. doi: 10.1006/expr.1995.1124

Baxter, R. H., Steinert, S., Chelliah, Y., Volohonsky, G., Levashina, E. A., and Deisenhofer, J. (2010). A heterodimeric complex of the LRR proteins LRIM1 and APL1C regulates complement-like immunity in Anopheles gambiae. Proc. Natl. Acad. Sci. U.S.A. 107, 16817-16822. doi: 10.1073/pnas.10105 75107

Bell, J. K., Mullen, G. E., Leifer, C. A., Mazzoni, A., Davies, D. R., and Segal, D. M. (2003). Leucine-rich repeats and pathogen recognition in Toll-like receptors. Trends Immunol. 24, 528-533. doi: 10.1016/S1471-4906(03)00242-4

Belvin, M. P., and Anderson, K. V. (1996). A conserved signaling pathway: the Drosophila toll-dorsal pathway. Annu. Rev. Cell Dev. Biol. 12, 393-416. doi: 10.1146/annurev.cellbio.12.1.393

Bokoch, G. M. (2005). Regulation of innate immunity by Rho GTPases. Trends Cell Biol. 15, 163-171. doi: 10.1016/j.tcb.2005.01.002

Boman, H. G., and Hultmark, D. (1981). Cell-free immunity in insects. Trends Biochem. Sci. 6, 3. doi: 10.1146/annurev.mi.41.100187.000535

Bubici, C., Papa, S., Dean, K., and Franzoso, G. (2006). Mutual cross-talk between reactive oxygen species and nuclear factor-kappa B: molecular basis and biological significance. Oncogene 25, 6731-6748. doi: 10.1038/sj.onc. 1209936

Buchon, N., Broderick, N. A., and Lemaitre, B. (2013). Gut homeostasis in a microbial world: insights from Drosophila melanogaster. Nat. Rev. Microbiol. 11, 615-626. doi: 10.1038/nrmicro3074

Buchon, N., Broderick, N. A., Poidevin, M., Pradervand, S., and Lemaitre, B. (2009). Drosophila intestinal response to bacterial infection: activation of host defense and stem cell proliferation. Cell Host Microbe 5, 200-211. doi: 10.1016/j.chom.2009.01.003

Bulet, P., Hetru, C., Dimarcq, J. L., and Hoffmann, D. (1999). Antimicrobial peptides in insects; structure and function. Dev. Comp. Immunol. 23, 329-344. doi: 10.1016/S0145-305X(99)00015-4

Burgdorfer, W., Barbour, A. G., Hayes, S. F., Benach, J. L., Grunwaldt, E., and Davis, J. P. (1982). Lyme disease-a tick-borne spirochetosis? Science 216, 1317-1319. doi: $10.1126 /$ science. 7043737

Carpi, G., Cagnacci, F., Wittekindt, N. E., Zhao, F., Qi, J., Tomsho, L. P., et al. (2011). Metagenomic profile of the bacterial communities associated with Ixodes ricinus ticks. PLoS ONE 6:e25604. doi: 10.1371/journal.pone.0025604

Chmelar, J., Oliveira, C. J., Rezacova, P., Francischetti, I. M., Kovarova, Z., Pejler, G., et al. (2011). A tick salivary protein targets cathepsin $G$ and chymase and inhibits host inflammation and platelet aggregation. Blood 117, 736-744. doi: 10.1182/blood-2010-06-293241

Christophides, G. K., Zdobnov, E., Barillas-Mury, C., Birney, E., Blandin, S., Blass, C., et al. (2002). Immunity-related genes and gene families in Anopheles gambiae. Science 298, 159-165. doi: 10.1126/science.1077136

Clay, K., Klyachko, O., Grindle, N., Civitello, D., Oleske, D., and Fuqua, C. (2008). Microbial communities and interactions in the lone star tick, Amblyomma americanum. Mol. Ecol. 17, 4371-4381. doi: 10.1111/j.1365-294X.2008. 03914.x

Crawley, J., Gonzalez-Porras, J. R., and Lane, D. A. (2011). "The coagulation cascade and its regulation," in Textbook of Pulmonary Vascular Disease, eds J. X. J. Yuan, C. A. Hales, S. L. Archer, J. G. N. Garcia, S. Rich, and J. B. West (New York, NY: Springer), 357-370.

Dai, J., Narasimhan, S., Zhang, L., Liu, L., Wang, P., and Fikrig, E. (2010). Tick histamine release factor is critical for Ixodes scapularis engorgement and transmission of the lyme disease agent. PLoS Pathog. 6:e1001205. doi: 10.1371/journal.ppat.1001205

Dam, T. K., and Brewer, C. F. (2010). Lectins as pattern recognition molecules: the effects of epitope density in innate immunity. Glycobiology 20, 270-279. doi: 10.1093/glycob/cwp186

Das, S., Banerjee, G., Deponte, K., Marcantonio, N., Kantor, F. S., and Fikrig, E. (2001). Salp25D, an Ixodes scapularis antioxidant, is 1 of 14 immunodominant antigens in engorged tick salivary glands. J. Infect. Dis. 184, 1056-1064. doi: $10.1086 / 323351$
Davies, S. (2000). Nitric oxide signalling in insects. Insect Biochem. Mol. Biol. 30, 1123-1138. doi: 10.1016/S0965-1748(00)00118-1

De Gregorio, E., Spellman, P. T., Tzou, P., Rubin, G. M., and Lemaitre, B. (2002). The Toll and IMD pathways are the major regulators of the immune response in Drosophila. EMBO J. 21, 2568-2579. doi: 10.1093/emboj/21.11.2568

Deken, X. D., Corvilain, B., Dumont, J. E., and Miot, F. (2013). Roles of DUOXmediated hydrogen peroxide in metabolism, host defense, and signaling. Antioxid. Redox Signal. 20, 2776-2793. doi: 10.1089/ars.2013.5602

Dias, F. A., Gandara, A. C., Queiroz-Barros, F. G., Oliveira, R. L., Sorgine, M. H., Braz, G. R., et al. (2013). Ovarian dual oxidase (Duox) activity is essential for insect eggshell hardening and waterproofing. J. Biol. Chem. 288, 35058-35067. doi: 10.1074/jbc.M113.522201

Dillon, R. J., and Dillon, V. M. (2004). The gut bacteria of insects: nonpathogenic interactions. Annu. Rev. Entomol. 49, 71-92. doi: 10.1146/annurev.ento.49. 061802.123416

Dimopoulos, G., Casavant, T. L., Chang, S., Scheetz, T., Roberts, C., Donohue, M., et al. (2000). Anopheles gambiae pilot gene discovery project: identification of mosquito innate immunity genes from expressed sequence tags generated from immune-competent cell lines. Proc. Natl. Acad. Sci. U.S.A. 97, 6619-6624. doi: 10.1073/pnas.97.12.6619

Dimopoulos, G., Seeley, D., Wolf, A., and Kafatos, F. C. (1998). Malaria infection of the mosquito Anopheles gambiae activates immune-responsive genes during critical transition stages of the parasite life cycle. EMBO J. 17, 6115-6123. doi: 10.1093/emboj/17.21.6115

Dong, Y., Aguilar, R., Xi, Z., Warr, E., Mongin, E., and Dimopoulos, G. (2006). Anopheles gambiae immune responses to human and rodent Plasmodium parasite species. PLoS Pathog. 2:e52. doi: 10.1371/journal.ppat.0020052

Edens, W. A., Sharling, L., Cheng, G., Shapira, R., Kinkade, J. M., Lee, T., et al. (2001). Tyrosine cross-linking of extracellular matrix is catalyzed by Duox, a multidomain oxidase/peroxidase with homology to the phagocyte oxidase subunit gp91phox. J. Cell Biol. 154, 879-891. doi: 10.1083/jcb.200103132

Elrod-Erickson, M., Mishra, S., and Schneider, D. (2000). Interactions between the cellular and humoral immune responses in Drosophila. Curr. Biol. 10, 781-784. doi: 10.1016/S0960-9822(00)00569-8

Enkhbayar, P., Kamiya, M., Osaki, M., Matsumoto, T., and Matsushima, N. (2004). Structural principles of leucine-rich repeat (LRR) proteins. Proteins 54, 394-403. doi: 10.1002/prot.10605

Etienne-Manneville, S., and Hall, A. (2002). Rho GTPases in cell biology. Nature 420, 629-635. doi: 10.1038/nature01148

Ferrandon, D., Imler, J. L., Hetru, C., and Hoffmann, J. A. (2007). The Drosophila systemic immune response: sensing and signalling during bacterial and fungal infections. Nat. Rev. Immunol. 7, 862-874. doi: 10.1038/nri2194

Fraiture, M., Baxter, R. H., Steinert, S., Chelliah, Y., Frolet, C., Quispe-Tintaya, W., et al. (2009). Two mosquito LRR proteins function as complement control factors in the TEP1-mediated killing of Plasmodium. Cell Host Microbe 5, 273-284. doi: 10.1016/j.chom.2009.01.005

Fraser, C. M., Casjens, S., Huang, W. M., Sutton, G. G., Clayton, R., Lathigra, R., et al. (1997). Genomic sequence of a Lyme disease spirochaete, Borrelia burgdorferi. Nature 390, 580-586. doi: 10.1038/37551

Fujita, T. (2002). Evolution of the lectin-complement pathway and its role in innate immunity. Nat. Rev. Immunol. 2, 346-353. doi: 10.1038/nri800

Geiszt, M., and Leto, T. L. (2004). The Nox family of NAD(P)H oxidases: host defense and beyond. J. Biol. Chem. 279, 51715-51718. doi: 10.1074/jbc.R400024200

Gillespie, R. D., Dolan, M. C., Piesman, J., and Titus, R. G. (2001). Identification of an IL-2 binding protein in the saliva of the Lyme disease vector tick, Ixodes scapularis. J. Immunol. 166, 4319-4326. doi: 10.4049/jimmunol.166.7.4319

Gorman, M. J., and Paskewitz, S. M. (2001). Serine proteases as mediators of mosquito immune responses. Insect Biochem. Mol. Biol. 31, 257-262. doi: 10.1016/S0965-1748(00)00145-4

Govind, S., and Nehm, R. H. (2004). Innate immunity in fruit flies: a textbook example of genomic recycling. PLoS Biol. 2:E276. doi: 10.1371/journal.pbio.0020276

Grubhoffer, L., Golovchenko, M., Vancova, M., Zacharovova-Slavickova, K., Rudenko, N., and Oliver, J. H. Jr. (2005). Lyme borreliosis: insights into tick-/host-borrelia relations. Folia Parasitol. (Praha) 52, 279-294. doi: $10.14411 /$ fp.2005.039

Grubhoffer, L., Hypsa, V., and Volf, P. (1997). Lectins (hemagglutinins) in the gut of the important disease vectors. Parasite 4, 203-216. 
Grubhoffer, L., and Jindrak, L. (1998). Lectins and tick-pathogen interactions: a minireview. Folia Parasitol. (Praha) 45, 9-13.

Grubhoffer, L., Kovar, V., and Rudenko, N. (2004). Tick lectins: structural and functional properties. Parasitology 129(Suppl.), S113-S125. doi: $10.1017 /$ S0031182004004858

Gulley, M. M., Zhang, X., and Michel, K. (2013). The roles of serpins in mosquito immunology and physiology. J. Insect Physiol. 59, 138-147. doi: 10.1016/j.jinsphys.2012.08.015

Gupta, L., Molina-Cruz, A., Kumar, S., Rodrigues, J., Dixit, R., Zamora, R. E., et al. (2009). The STAT pathway mediates late-phase immunity against Plasmodium in the mosquito Anopheles gambiae. Cell Host Microbe 5, 498-507. doi: 10.1016/j.chom.2009.04.003

Hajdusek, O., Sima, R., Ayllon, N., Jalovecka, M., Perner, J., de la Fuente, J., et al. (2013). Interaction of the tick immune system with transmitted pathogens. Front. Cell. Infect. Microbiol. 3:26. doi: 10.3389/fcimb.2013.00026

Hetru, C., Troxler, L., and Hoffmann, J. A. (2003). Drosophila melanogaster antimicrobial defense. J. Infect. Dis. 187(Suppl. 2), S327-S334. doi: 10.1086/ 374758

Hill, C. A., and Wikel, S. K. (2005). The Ixodes scapularis Genome Project: an opportunity for advancing tick research. Trends Parasitol. 21, 151-153. doi: 10.1016/j.pt.2005.02.004

Hoffmann, J. A., Kafatos, F. C., Janeway, C. A., and Ezekowitz, R. A. (1999). Phylogenetic perspectives in innate immunity. Science 284, 1313-1318. doi: 10.1126/science.284.5418.1313

Hoffmann, J. A., and Reichhart, J. M. (2002). Drosophila innate immunity: an evolutionary perspective. Nat. Immunol. 3, 121-126. doi: 10.1038/ni0202-121

Hooper, L. V., Littman, D. R., and Macpherson, A. J. (2012). Interactions between the microbiota and the immune system. Science 336, 1268-1273. doi: 10.1126/science. 1223490

Hovius, J. W., Levi, M., and Fikrig, E. (2008). Salivating for knowledge: potential pharmacological agents in tick saliva. PLoS Med. 5:e43. doi: 10.1371/journal.pmed.0050043

Hynes, W. L., Ceraul, S. M., Todd, S. M., Seguin, K. C., and Sonenshine, D. E. (2005). A defensin-like gene expressed in the black-legged tick, Ixodes scapularis. Med. Vet. Entomol. 19, 339-344. doi: 10.1111/j.1365-2915.2005.00579.x

Imler, J. L., and Bulet, P. (2005). Antimicrobial peptides in Drosophila: structures, activities and gene regulation. Chem. Immunol. Allergy 86, 1-21. doi: $10.1159 / 000086648$

Inoue, N., Hanada, K., Tsuji, N., Igarashi, I., Nagasawa, H., Mikami, T., et al. (2001). Characterization of phagocytic hemocytes in Ornithodoros moubata (Acari: Ixodidae). J. Med. Entomol. 38, 514-519. doi: 10.1603/0022-258538.4.514

Irving, P., Troxler, L., Heuer, T. S., Belvin, M., Kopczynski, C., Reichhart, J. M., et al. (2001). A genome-wide analysis of immune responses in Drosophila. Proc. Natl. Acad. Sci. U.S.A. 98, 15119-15124. doi: 10.1073/pnas.261573998

James, A. A. (2003). Blocking malaria parasite invasion of mosquito salivary glands. J. Exp. Biol. 206, 3817-3821. doi: 10.1242/jeb.00616

James, S. L. (1995). Role of nitric oxide in parasitic infections. Microbiol. Rev. 59, 533-547.

Janeway, C. A. Jr., and Medzhitov, R. (2002). Innate immune recognition. Annu. Rev. Immunol. 20, 197-216. doi: 10.1146/annurev.immunol.20.083001. 084359

Jaworski, D. C., Zou, Z., Bowen, C. J., Wasala, N. B., Madden, R., Wang, Y., et al. (2010). Pyrosequencing and characterization of immune response genes from the American dog tick, Dermacentor variabilis (L.). Insect Mol. Biol. 19, 617-630. doi: 10.1111/j.1365-2583.2010.01037.x

Jiravanichpaisal, P., Lee, B. L., and Soderhall, K. (2006). Cell-mediated immunity in arthropods: hematopoiesis, coagulation, melanization and opsonization. Immunobiology 211, 213-236. doi: 10.1016/j.imbio.2005.10.015

Johns, R., Ohnishi, J., Broadwater, A., Sonenshine, D. E., De Silva, A. M., and Hynes, W. L. (2001). Contrasts in tick innate immune responses to Borrelia burgdorferi challenge: immunotolerance in Ixodes scapularis versus immunocompetence in Dermacentor variabilis (Acari: Ixodidae). J. Med. Entomol. 38, 99-107. doi: 10.1603/0022-2585-38.1.99

Jongejan, F., and Uilenberg, G. (2004). The global importance of ticks. Parasitology 129 (Suppl.), S3-S14. doi: 10.1017/S0031182004005967

Kadota, K., Satoh, E., Ochiai, M., Inoue, N., Tsuji, N., Igarashi, I., et al. (2002). Existence of phenol oxidase in the argasid tick Ornithodoros moubata. Parasitol. Res. 88, 781-784. doi: 10.1007/s00436-002-0664-x
Kamada, N., Seo, S. U., Chen, G. Y., and Nunez, G. (2013). Role of the gut microbiota in immunity and inflammatory disease. Nat. Rev. Immunol. 13, 321-335. doi: $10.1038 /$ nri3430

Kaneko, T., and Silverman, N. (2005). Bacterial recognition and signalling by the Drosophila IMD pathway. Cell. Microbiol. 7, 461-469. doi: 10.1111/j.14625822.2005.00504.x

Kanost, M. R. (1999). Serine proteinase inhibitors in arthropod immunity. Dev. Comp. Immunol. 23, 291-301. doi: 10.1016/S0145-305X(99) 00012-9

Kibuka-Sebitosi, E. (2006). Potential role of lectins in ticks: Rhipicephalus appendicula and Rhipicephalus pulchellus. Syst. Appl. Acarol. Publ. 21, 14.

Kim, S. H., and Lee, W. J. (2014). Role of DUOX in gut inflammation: lessons from model of gut-microbiota interactions. Front. Cell. Infect. Microbiol. 3:116. doi 10.3389/fcimb.2013.00116

Kobe, B., and Kajava, A. V. (2001). The leucine-rich repeat as a protein recognition motif. Curr. Opin. Struct. Biol. 11, 725-732. doi: 10.1016/S0959440X(01)00266-4

Kopacek, P., Hajdusek, O., Buresova, V., and Daffre, S. (2010). Tick innate immunity. Adv. Exp. Med. Biol. 708, 137-162. doi: 10.1007/978-1-4419-8059-5_8

Kuhn, K. H., Uhlir, J., and Grubhoffer, L. (1996). Ultrastructural localization of a sialic acid-specific hemolymph lectin in the hemocytes and other tissues of the hard tick Ixodes ricinus (Acari; Chelicerata). Parasitol. Res. 82, 215-221. doi: 10.1007/s004360050098

Kumar, S., Molina-Cruz, A., Gupta, L., Rodrigues, J., and Barillas-Mury, C. (2010). A peroxidase/dual oxidase system modulates midgut epithelial immunity in Anopheles gambiae. Science 327, 1644-1648. doi: 10.1126/science. 1184008

Kung, F., Anguita, J., and Pal, U. (2013). Borrelia burgdorferi and tick proteins supporting pathogen persistence in the vector. Future Microbiol. 8, 41-56. doi: $10.2217 / \mathrm{fmb} .12 .121$

Lazzaro, B. P., and Rolff, J. (2011). Immunology. Danger, microbes, and homeostasis. Science 332, 43-44. doi: 10.1126/science.1200486

Lemaitre, B. (2004). The road to Toll. Nat. Rev. Immunol. 4, 521-527. doi: $10.1038 /$ nri1390

Liu, L., Dai, J., Zhao, Y. O., Narasimhan, S., Yang, Y., Zhang, L., et al. (2012). Ixodes scapularis JAK-STAT pathway regulates tick antimicrobial peptides, thereby controlling the agent of human granulocytic anaplasmosis. J. Infect. Dis. 206, 1233-1241. doi: 10.1093/infdis/jis484

Macpherson, A. J., and Harris, N. L. (2004). Interactions between commensal intestinal bacteria and the immune system. Nat. Rev. Immunol. 4, 478-485. doi: 10.1038/nri1373

Matova, N., and Anderson, K. V. (2006). Rel/NF-kappaB double mutants reveal that cellular immunity is central to Drosophila host defense. Proc. Natl. Acad. Sci. U.S.A. 103, 16424-16429. doi: 10.1073/pnas.0605721103

Mattila, J. T., Munderloh, U. G., and Kurtti, T. J. (2007). Phagocytosis of the Lyme disease spirochete, Borrelia burgdorferi, by cells from the ticks, Ixodes scapularis and Dermacentor andersoni, infected with an endosymbiont, Rickettsia peacockii. J. Insect Sci. 7, 58. doi: 10.1673/031.007.5801

Molina-Cruz, A., Dejong, R. J., Charles, B., Gupta, L., Kumar, S., JaramilloGutierrez, G., et al. (2008). Reactive oxygen species modulate Anopheles gambiae immunity against bacteria and Plasmodium. J. Biol. Chem. 283, 3217-3223. doi: 10.1074/jbc.M705873200

Morgan, M. J., and Liu, Z. G. (2011). Crosstalk of reactive oxygen species and NFkappaB signaling. Cell Res. 21, 103-115. doi: 10.1038/cr.2010.178

Muleng, A., Sugino, M., Nakajim, M., Sugimoto, C., and Onuma, M. (2001). TickEncoded serine proteinase inhibitors (serpins); potential target antigens for tick vaccine development. J. Vet. Med. Sci. 63, 1063-1069. doi: 10.1292/jvms. 63.1063

Mulenga, A., Khumthong, R., and Chalaire, K. C. (2009). Ixodes scapularis tick serine proteinase inhibitor (serpin) gene family; annotation and transcriptional analysis. BMC Genomics 10:217. doi: 10.1186/1471-2164-10-217

Nakajima, Y., van der Goes van Naters-Yasui, A., Taylor, D., and Yamakawa, M. (2002). Antibacterial peptide defensin is involved in midgut immunity of the soft tick, Ornithodoros moubata. Insect Mol. Biol. 11, 611-618. doi: 10.1046/j.1365-2583.2002.00372.x

Narasimhan, S., Koski, R. A., Beaulieu, B., Anderson, J. F., Ramamoorthi, N., Kantor, F., et al. (2002). A novel family of anticoagulants from the saliva of Ixodes scapularis. Insect Mol. Biol. 11, 641-650. doi: 10.1046/j.1365-2583.2002. 00375.x 
Narasimhan, S., Montgomery, R. R., Deponte, K., Tschudi, C., Marcantonio, N., Anderson, J. F., et al. (2004). Disruption of Ixodes scapularis anticoagulation by using RNA interference. Proc. Natl. Acad. Sci. U.S.A. 101, 1141-1146. doi: 10.1073/pnas.0307669100

Narasimhan, S., Rajeevan, N., Liu, L., Zhao, Y. O., Heisig, J., Pan, J., et al. (2014). Gut Microbiota of the tick vector Ixodes scapularis modulate colonization of the Lyme disease spirochete. Cell Host Microbe 15, 58-71. doi: 10.1016/j.chom.2013.12.001

Narasimhan, S., Sukumaran, B., Bozdogan, U., Thomas, V., Liang, X., Deponte, K., et al. (2007). A tick antioxidant facilitates the Lyme disease agent's successful migration from the mammalian host to the arthropod vector. Cell Host Microbe 2, 7-18. doi: 10.1016/j.chom.2007.06.001

Osta, M. A., Christophides, G. K., and Kafatos, F. C. (2004). Effects of mosquito genes on Plasmodium development. Science 303, 2030-2032. doi: 10.1126/science. 1091789

Owusu-Ansah, E., and Banerjee, U. (2009). Reactive oxygen species prime Drosophila haematopoietic progenitors for differentiation. Nature 461, 537-541. doi: 10.1038/nature08313

Pagel Van Zee, J., Geraci, N. S., Guerrero, F. D., Wikel, S. K., Stuart, J. J., Nene, V. M., et al. (2007). Tick genomics: the Ixodes genome project and beyond. Int. J. Parasitol. 37, 1297-1305. doi: 10.1016/j.ijpara.2007.05.011

Pal, U., and Fikrig, E. (2010). “Tick Interactions," in Borrelia, Molecular Biology, Host Interaction and Pathogenesis, eds D. S. Samuels and J. D. Radolf (Norfolk: Caister Academic Press), 279-298.

Pan, X., Zhou, G., Wu, J., Bian, G., Lu, P., Raikhel, A. S., et al. (2012). Wolbachia induces reactive oxygen species (ROS)-dependent activation of the Toll pathway to control dengue virus in the mosquito Aedes aegypti. Proc. Natl. Acad. Sci. U.S.A. 109, E23-E31. doi: 10.1073/pnas.1116932108

Pereira, L. S., Oliveira, P. L., Barja-Fidalgo, C., and Daffre, S. (2001). Production of reactive oxygen species by hemocytes from the cattle tick Boophilus microplus. Exp. Parasitol. 99, 66-72. doi: 10.1006/expr.2001.4657

Povelones, M., Upton, L. M., Sala, K. A., and Christophides, G. K. (2011). Structure-function analysis of the Anopheles gambiae LRIM1/APL1C complex and its interaction with complement C3-like protein TEP1. PLoS Pathog. 7:e1002023. doi: 10.1371/journal.ppat.1002023

Povelones, M., Waterhouse, R. M., Kafatos, F. C., and Christophides, G. K. (2009). Leucine-rich repeat protein complex activates mosquito complement in defense against Plasmodium parasites. Science 324, 258-261. doi: 10.1126/science. 1171400

Rawlings, J. S., Rosler, K. M., and Harrison, D. A. (2004). The JAK/STAT signaling pathway. J. Cell Sci. 117, 1281-1283. doi: 10.1242/jcs.00963

Reichhart, J. M., Gubb, D., and Leclerc, V. (2011). The Drosophila serpins: multiple functions in immunity and morphogenesis. Meth. Enzymol. 499, 205-225. doi: 10.1016/B978-0-12-386471-0.00011-0

Round, J. L., and Mazmanian, S. K. (2009). The gut microbiota shapes intestinal immune responses during health and disease. Nat. Rev. Immunol. 9, 313-323. doi: $10.1038 /$ nri2515

Rudenko, N., Golovchenko, M., Edwards, M. J., and Grubhoffer, L. (2005). Differential expression of Ixodes ricinus tick genes induced by blood feeding or Borrelia burgdorferi infection. J. Med. Entomol. 42, 36-41. doi: 10.1603/00222585(2005)042[0036:DEOIRT]2.0.CO;2

Saito, Y., Konnai, S., Yamada, S., Imamura, S., Nishikado, H., Ito, T., et al. (2009). Identification and characterization of antimicrobial peptide, defensin, in the taiga tick, Ixodes persulcatus. Insect Mol. Biol. 18, 531-539. doi: 10.1111/j.13652583.2009.00897.x

Saul, A. (2004). The mosquito's innate sting. Nat. Med. 10, 455-457. doi: 10.1038/nm0504-455

Schleifer, K. H., and Kandler, O. (1972). Peptidoglycan types of bacterial cell walls and their taxonomic implications. Bacteriol. Rev. 36, 407-477.

Schuijt, T. J., Coumou, J., Narasimhan, S., Dai, J., Deponte, K., Wouters, D., et al. (2011). A tick mannose-binding lectin inhibitor interferes with the vertebrate complement cascade to enhance transmission of the lyme disease agent. Cell Host Microbe 10, 136-146. doi: 10.1016/j.chom.2011. 06.010

Schuijt, T. J., van der Poll, T., de Vos, W. M., and Wiersinga, W. J. (2013). The intestinal microbiota and host immune interactions in the critically ill. Trends Microbiol. 21, 221-229. doi: 10.1016/j.tim.2013.02.001

Sharma, R., Yang, Y., Sharma, A., Awasthi, S., and Awasthi, Y. C. (2004). Antioxidant role of glutathione S-transferases: protection against oxidant toxicity and regulation of stress-mediated apoptosis. Antioxid. Redox Signal. 6, 289-300. doi: $10.1089 / 152308604322899350$

Shuai, K., Ziemiecki, A., Wilks, A. F., Harpur, A. G., Sadowski, H. B., Gilman, M. Z., et al. (1993). Polypeptide signalling to the nucleus through tyrosine phosphorylation of Jak and Stat proteins. Nature 366, 580-583. doi: 10.1038/ 366580a0

Sideri, M., Tsakas, S., Markoutsa, E., Lampropoulou, M., and Marmaras, V. J. (2008). Innate immunity in insects: surface-associated dopa decarboxylasedependent pathways regulate phagocytosis, nodulation and melanization in medfly haemocytes. Immunology 123, 528-537. doi: 10.1111/j.13652567.2007.02722.x

Sojka, D., Francischetti, I. M., Calvo, E., and Kotsyfakis, M. (2011). Cysteine proteases from bloodfeeding arthropod ectoparasites. Adv. Exp. Med. Biol. 712, 177-191. doi: 10.1007/978-1-4419-8414-2_11

Sonenshine, D. E. (1993). Biology of Ticks. New York, NY: Oxford University Press. Sonenshine, D. E., Ceraul, S. M., Hynes, W. E., Macaluso, K. R., and Azad, A. F. (2002). Expression of defensin-like peptides in tick hemolymph and midgut in response to challenge with Borrelia burgdorferi, Escherichia coli and Bacillus subtilis. Exp. Appl. Acarol. 28, 127-134. doi: 10.1023/A:10253543 26877

Sonenshine, D. E., Hynes, W. L., Ceraul, S. M., Mitchell, R., and Benzine, T. (2005). Host blood proteins and peptides in the midgut of the tick Dermacentor variabilis contribute to bacterial control. Exp. Appl. Acarol. 36, 207-223. doi: 10.1007/s10493-005-2564-0

Souza-Neto, J. A., Sim, S., and Dimopoulos, G. (2009). An evolutionary conserved function of the JAK-STAT pathway in anti-dengue defense. Proc. Natl. Acad. Sci. U.S.A. 106, 17841-17846. doi: 10.1073/pnas.0905006106

Takayama, K., Rothenberg, R. J., and Barbour, A. G. (1987). Absence of lipopolysaccharide in the Lyme disease spirochete, Borrelia burgdorferi. Infect. Immun. 55, 2311-2313.

Tanji, T., Hu, X., Weber, A. N., and Ip, Y. T. (2007). Toll and IMD pathways synergistically activate an innate immune response in Drosophila melanogaster. Mol. Cell. Biol. 27, 4578-4588. doi: 10.1128/MCB.01814-06

Tanji, T., and Ip, Y. T. (2005). Regulators of the Toll and IMD pathways in the Drosophila innate immune response. Trends Immunol. 26, 193-198. doi: 10.1016/j.it.2005.02.006

Thannickal, V. J., and Fanburg, B. L. (2000). Reactive oxygen species in cell signaling. Am. J. Physiol. Lung Cell. Mol. Physiol. 279, L1005-L1028.

Theopold, U., Schmidt, O., Soderhall, K., and Dushay, M. S. (2004). Coagulation in arthropods: defence, wound closure and healing. Trends Immunol. 25, 289-294. doi: 10.1016/j.it.2004.03.004

Tokunaga, F., Miyata, T., Nakamura, T., Morita, T., Kuma, K., Miyata, T., et al. (1987). Lipopolysaccharide-sensitive serine-protease zymogen (factor C) of horseshoe crab hemocytes. Identification and alignment of proteolytic fragments produced during the activation show that it is a novel type of serine protease. Eur. J. Biochem. 167, 405-416. doi: 10.1111/j.1432-1033.1987. tb13352.x

Uhlir, J., Grubhoffer, L., and Volf, P. (1996). Novel agglutinin in the midgut of the tick Ixodes ricinus. Folia Parasitol. (Praha) 43, 233-239.

Ullmann, A. J., Lima, C. M., Guerrero, F. D., Piesman, J., and Black, W. C. T. (2005). Genome size and organization in the blacklegged tick, Ixodes scapularis and the Southern cattle tick, Boophilus microplus. Insect Mol. Biol. 14, 217-222. doi: 10.1111/j.1365-2583.2005.00551.x

Valanne, S., Wang, J. H., and Ramet, M. (2011). The Drosophila Toll signaling pathway. J. Immunol. 186, 649-656. doi: 10.4049/jimmunol.1002302

Vilmos, P., and Kurucz, E. (1998). Insect immunity: evolutionary roots of the mammalian innate immune system. Immunol. Lett. 62, 59-66. doi: 10.1016/S01652478(98)00023-6

Walters, M. N., and Papadimitriou, J. M. (1978). Phagocytosis: a review. CRC Crit. Rev. Toxicol. 5, 377-421. doi: 10.3109/10408447809081012

Wandurska-Nowak, E. (2004). [The role of nitric oxide (NO) in parasitic infections]. Wiad. Parazytol. 50, 665-678.

Wikel, S. K. (1996). Host immunity to ticks. Annu. Rev. Entomol. 41, 1-22. doi: 10.1146/annurev.en.41.010196.000245

Xi, Z., Ramirez, J. L., and Dimopoulos, G. (2008). The Aedes aegypti toll pathway controls dengue virus infection. PLoS Pathog. 4:e1000098. doi: 10.1371/journal.ppat. 1000098

Yassine, H., and Osta, M. A. (2010). Anopheles gambiae innate immunity. Cell. Microbiol. 12, 1-9. doi: 10.1111/j.1462-5822.2009.01388.x 
Zambon, R. A., Nandakumar, M., Vakharia, V. N., and Wu, L. P. (2005). The Toll pathway is important for an antiviral response in Drosophila. Proc. Natl. Acad. Sci. U.S.A. 102, 7257-7262. doi: 10.1073/pnas.0409181102

Zhang, Z. T., and Zhu, S. Y. (2009). Drosomycin, an essential component of antifungal defence in Drosophila. Insect Mol. Biol. 18, 549-556. doi: 10.1111/j.13652583.2009.00907.x

Zhu, Y., Ragan, E. J., and Kanost, M. R. (2010). Leureptin: a soluble, extracellular leucine-rich repeat protein from Manduca sexta that binds lipopolysaccharide. Insect Biochem. Mol. Biol. 40, 713-722. doi: 10.1016/j.ibmb.2010.07.002

Conflict of Interest Statement: The authors declare that the research was conducted in the absence of any commercial or financial relationships that could be construed as a potential conflict of interest.
Received: 14 May 2014; paper pending published: 21 June 2014; accepted: 05 August 2014; published online: 22 August 2014.

Citation: Smith AA and Pal U (2014) Immunity-related genes in Ixodes scapularisperspectives from genome information. Front. Cell. Infect. Microbiol. 4:116. doi: $10.3389 / f_{\text {cimb. }} 2014.00116$

This article was submitted to the journal Frontiers in Cellular and Infection Microbiology.

Copyright (C) 2014 Smith and Pal. This is an open-access article distributed under the terms of the Creative Commons Attribution License (CC BY). The use, distribution or reproduction in other forums is permitted, provided the original author(s) or licensor are credited and that the original publication in this journal is cited, in accordance with accepted academic practice. No use, distribution or reproduction is permitted which does not comply with these terms. 